\title{
Natural Plant Fiber Composites-Constituent Properties and Challenges in Numerical Modeling and Simulations
}

\author{
Yucheng Zhong*, ${ }^{*}$, Umeyr Kureemun ${ }^{\dagger}$, \\ Tran Le Quan Ngoc ${ }^{\ddagger}$ and Heow Pueh Lee ${ }^{\dagger, \S}$ \\ *Hubei Key Laboratory of Theory and \\ Application of Advanced Materials Mechanics \\ Wuhan University of Technology, 122 Luoshi Road \\ Wuhan, P. R. China \\ $\dagger$ Department of Mechanical Engineering \\ National University of Singapore \\ 9 Engineering Drive 1, Singapore 117576 \\ ${ }^{\ddagger}$ Singapore Institute of Manufacturing Technology (SIMTech) \\ A*Star, 71 Nanyang Drive, Singapore 638075 \\ $\S_{\text {mpeleehp@nus.edu.sg }}$ \\ Received 19 September 2016 \\ Revised 24 April 2017 \\ Accepted 25 April 2017 \\ Published 8 June 2017
}

\begin{abstract}
Natural fibers are extracted from natural resources such as stems of plants. In contrast to synthetic fibers (e.g., carbon fibers), natural fibers are from renewable resources and are eco-friendlier. Plant fibers are important members of natural fibers. Review papers discussing the microstructures, performances and applications of natural plant fiber composites are available in the literature. However, there are relatively fewer review reports focusing on the modeling of the mechanical properties of plant fiber composites. The microstructures and mechanical behavior of plant fiber composites are briefly introduced by highlighting their characteristics that need to be considered prior to modeling. Numerical works that have already been carried out are discussed and summarized. Unlike synthetic fibers, natural plant fiber composites have not received sufficient attention in terms of numerical simulations. Existing technical challenges in this subject are summarized to provide potential opportunities for future research.
\end{abstract}

Keywords: Natural fibers; composites; flax; numerical; simulation; acoustic.

\section{Introduction}

A composite material consists of two or more constituent materials which are physically separable and distinct. In the aerospace industry where weight saving is of

$\S$ Corresponding author.

This is an Open Access article published by World Scientific Publishing Company. It is distributed under the terms of the Creative Commons Attribution 4.0 (CC-BY) License. Further distribution of this work is permitted, provided the original work is properly cited. 
particular concern to reduce fuel consumption and increase travel distance as well as cargo capacity, high-strength fibers such as carbon fiber and glass fiber are impregnated by polymeric matrices to produce composite structures. These composite materials are widely used in both secondary and primary structures of aircrafts due to their high specific strength and modulus. However, these fibers have their inherent problems, which include high cost and unsustainable sources. Compared to carbon and glass fibers, natural fibers bring about advantages including but not limited to lower cost, sustainability, bio-degradability and less environmental impact Mohanty et al., 2002; Pickering et al., 2016.

The big family of natural fibers includes plant fibers (wood or vegetable), animal fibers such as silk, and mineral fibers such as asbestos Ahmad et al., 2015; Sanyang et al., 2016. It is also a feasible and economical way to extract fibers from agricultural and industrial waste and residues [Väisänen et al., 2016]. Natural plant fibers such as flax, jute, hemp, sisal, ramie, and kenaf fibers were extensively investigated and adopted in many applications Faruk et al., 2014. These natural plant fibers have good mechanical properties and renewable raw material sources. Compared to carbon and glass fibers, these natural fibers have lower price and are bio-degradable. Pil et al. 2016] compared the properties of flax, glass and carbon fiber unidirectional composites as a function of the fiber volume fraction. The specific bending stiffness of flax composites was slightly higher than that of glass fiber composites for fiber volume fraction between $30 \%$ and $60 \%$. These characteristics of natural plant fibers and their composites have attracted attention from both the industry and academics.

With the objective to reduce weight, cost and environmental impact, the automotive industry became the largest consumers of plant fiber composites which are used on structures such as door panels Al-Oqla and Sapuan, 2014, seat backs, dashboard, pillar cover, engine insulation, headliner panel and parcel shelves Maity et al., 2014; Karus and Kaup, 2002; Koronis et al., 2013; Nadlene et al., 2016; Marsh, 2003; Bharath and Basavarajappa, 2016; Holbery and Houston, 2006]. As a good insulating material, plant fiber composites are used in construction industry Korienic et al., 2016; Kalvankar and Uddin, 2012; Christian and Billington, 2011]. There was reported investigation which aimed to design and manufacture wind turbine blades using natural fibers Park, 2016]. Plant fiber composites have excellent vibration damping properties. This is a merit when using these materials on sport equipment, such as bikes and tennis rackets Meredith et al., 2012; Mohammed et al., 2015. These bio-composites also become potential candidate materials for aircraft indoor structures due to their light weight and good mechanical properties Scarponi and Messano, 2015. Natural plant fiber composites have also permeated into the sound industry to fabricate musical instruments such as speaker kits, guitars and ukuleles Pil et al., 2016; Phillips and Lessard, 2012].

Research interests in natural plant fiber composites began to increase about two decades ago. However, research work reported by now concerning the numerical and analytical aspects of these materials is still limited as compared with carbon and 
glass fiber reinforced composites. Facca et al. 2007] presented a modified rule-ofmixture (ROM) strength equation for the prediction of the tensile strength of short fiber reinforced high-density polyethylene composites. The fact that fiber loading would affect the available fiber stress transfer area and eventually affect the tensile strength of the material was taken into consideration in the proposed micromechanical model by introducing a clustering parameter. Beckermann and Pickering 2009. applied surface treatment using a 5 wt. $\% \mathrm{NaOH}$ and 2 wt. $\% \mathrm{Na}_{2} \mathrm{SO}_{3}$ solution to hemp fibers and studied the tensile strength both experimentally and analytically. The theoretical composite strengths were determined by means of the Modified Rule of Mixtures and Bowyer-Bader models. The Bowyer-Bader model overestimated the strength of these short fiber reinforced composites as in reality the alignment of the fibers was not perfectly uniform. The mechanical property of plant fiber composites would degrade as a result of moisture uptake. Pan and Zhong [2015a] developed a micromechanical model for the prediction of the mechanical property degradation of sisal fiber composites due to moisture absorption. A damage variable was introduced to a modified Mori-Tanaka method to account for such circumstance. Kong et al. 2016 designed an automobile hood using flax fiber/vinyl ester composites. The hood's design load was aerodynamic load of $200 \mathrm{~km} / \mathrm{h}$ velocity. The stacking sequence and thickness was therefore decided. The structural analyses were performed using MSC. Nastran to obtain the stress and strain fields developed inside the composite hood under design load.

A number of researchers have presented useful and comprehensive review articles about plant fibers and their composites. Summerscales et al. 2010] reviewed the growth and harvesting process of flax fibers. Asdrubali et al. [2012] summarized the acoustic and thermal properties of common natural fibers such as hemp and flax. Common bio-composites, major class of biodegradable polymers, natural fibers, as well as their manufacturing techniques and properties were reviewed by Gurunathan et al. 2015. Good bonding between the natural fiber and polymer matrix is necessitated for effective load transfer between the constituents. Surface modification techniques for natural fibers including physical and chemical modifications were also reviewed Gurunathan et al., 2015. Dynamic mechanical analysis and dynamic mechanical properties of various types of natural fiber composites were reviewed in details by Saba et al. [2016. Yan et al. 2014] reviewed flax fibers and their composites. The structure, mechanical properties, manufacturing processes and durability of flax fiber and its composites were summarized Yan et al., 2014|. The sustainability aspect of natural fibers was specifically reviewed by Adekomava et al. 2016. Faruk et al. [2012] presented a detailed and comprehensive review on biocomposites. The fibers, common matrices, processing technologies and properties of biocomposites were discussed. Obstacles faced such as moisture absorption and future development were also introduced. However, there are limited review works focusing on the modeling of the mechanical behavior of natural plant fiber composites. 
This paper aims to provide readers a brief summary about numerical modeling and simulation works that have so far been done on natural plant fiber composites. The unique microstructures of plant fibers, with bast fibers in particular, and their composites are discussed as the implementation of material model during simulation depends on the microstructure of the constituents. Mechanical properties of plant fibers and their composites are discussed with the emphases placed on those aspects that need to be considered during simulation. Moreover, interests exist among manufacturers and consumers of natural plant fiber composites in their acoustic performance. Therefore, acoustic and vibration damping performance of natural plant fiber composites are also discussed.

\section{Microstructures of Plant Fibers and Their Composites}

Bast fibers which include flax, hemp, jute, kenaf and ramie fibers have good mechanical properties and are promising reinforcement materials. Take flax fiber for instance. The processing of flax fiber is illustrated in Fig. 1 Van de Weyenberg et al., 2003]. Retting, scutching and hackling are normally carried out to obtain natural fibers from flax plants. Retting dissolves or rots away much of the cellular tissues and pectins surrounding bast-fiber bundles, so as to facilitate separation of the fiber from the stem of green flax plants. Scutching completes the removal of the woody stem from flax fibers, whereas hackling is the process of separating fibers that are still clinging together. It is not difficult to understand from the manufacturing process of flax fiber that individual fibers in a fiber yarn are neither completely separated nor continuous. Carbon fibers and glass fibers are usually long fibers and called as endless fibers. However, natural fibers extracted from plants are not continuous and have limited length. Plant fibers are usually twisted to form fiber yarns which are later used to produce fiber fabrics.

The microstructures of natural plant fibers are markedly different from that of synthetic fibers. Typical SEM images of flax fibers are shown in Fig. 2 Baley, 2002]. Flax fibers consist mainly of cellulose polymer (40-70 wt.\%). These fibers are usually combinations of a number of concentric cell walls of different thicknesses. The structures of flax fibers at different scales are shown in Fig. 3 Charlet et al., 2007, 2010a. Flax fibers are extracted from the stems of flax fiber. Initially, flax fibers appear as bundles of fibers (fibers are not separated). These flax bundles are often referred to as technical flax fibers. Single flax fibers in the bundle are glued by pectin. These single flax fibers are termed as elementary flax fiber. The average diameter of an elementary flax fiber is 12-16 $\mu \mathrm{m}$ [Natural fibers, 2009; Yang and Li, 2012]. The concentric cell walls fall in three categories, i.e., primary cell wall, secondary cell wall and lumen Astley and Donald, 2003.

The outer cell walls are primary cell wall, which is normally thin compared to the secondary cell wall. The secondary cell wall consists of numerous cellulose microfibrils which are usually laid with a small angle with respect to the axis of the fiber (Fig. 3). This angle is usually called micro-fibrillar angle. The micro-fibrillar angle 


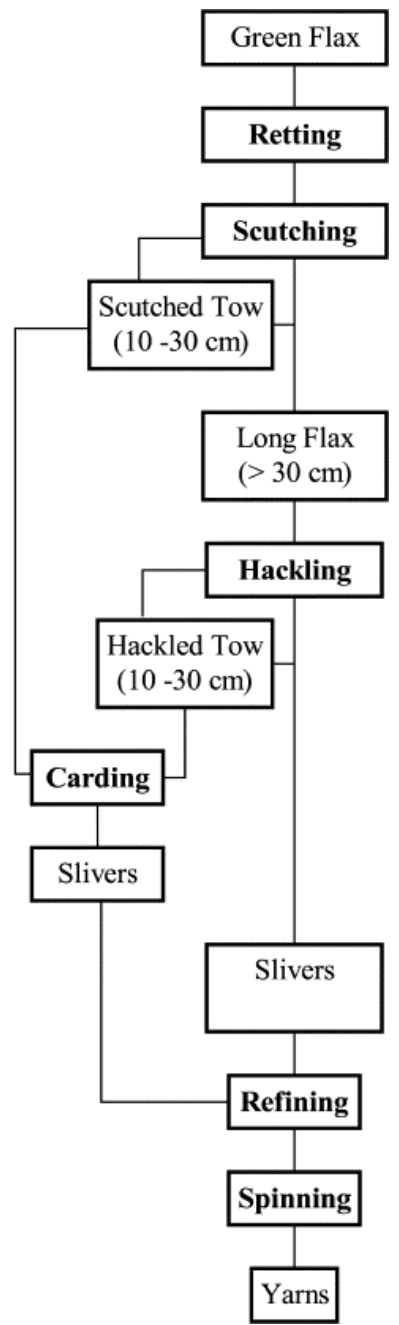

Fig. 1. Processing of flax fibers Van de Wevenberg et al., 2003].

is minimum in the secondary cell wall (around $10^{\circ}$ as shown in Fig. [3). These microfibrils are glued together by the amorphous hemicellulose and pectin. At nano-scale, a micro-fibril is essentially cellulose crystallites surrounded by hemicelluloses and pectin. The secondary cell wall typically constitutes $70 \mathrm{wt} . \%$ of a flax fiber and contributes to the majority of the load-carrying capability of the fiber Yan et al., 2014]. The concentric cylinder with an open channel at the center of the elementary flax fiber is called lumen. As illustrated in Fig. 2, the hollow part at the center of the fibers is called lumen. Cellulose and hemicellulose which is hygroscopic would absorb moisture. Once the moisture diffuses to the lumen and if the relative humidity is high enough $(>70 \%)$, capillary condensation will occur and water will condense within the lumen. 


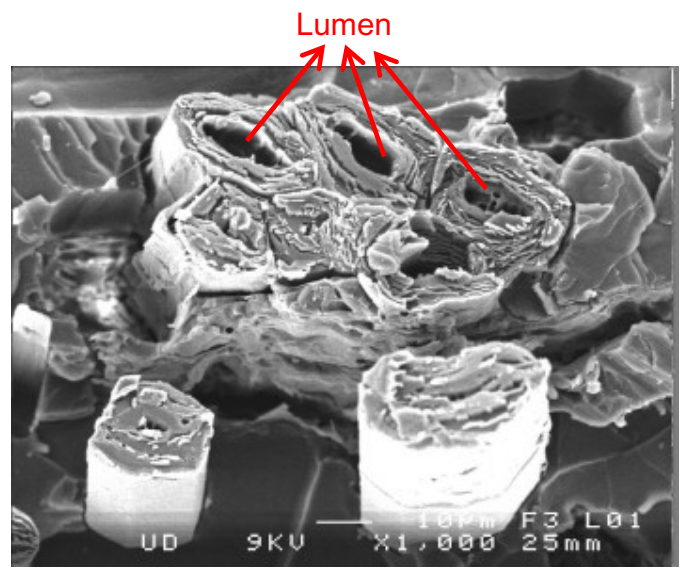

Fig. 2. Cross-section of a flax fiber/epoxy composite [Baley, 2002].
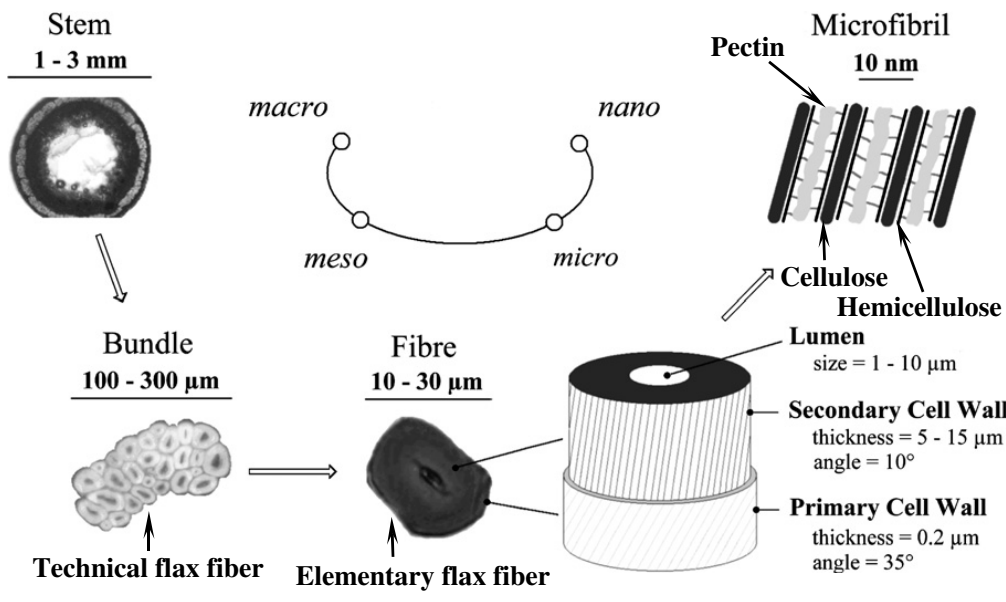

Fig. 3. Structure of a flax fiber Charlet et al., 2007, 2010a].

It is therefore not difficult to imagine that plant fibers with such microstructure are not isotropic materials. It is a more rigorous practice to model the natural plant fibers as transversely isotropic material. The microstructure of plant fibers, however, not only affects the material model to be selected during simulation. Carbon and glass fibers are usually of circular shape which is considered to be uniform along the fiber direction. The strength and modulus of fibers are calculated based on their cross-sectional area. Unlike synthetic fibers, it has been confirmed by many researchers that the cross-sectional shapes of plant fibers are irregular rather than circular Beakou and Charlet, 2013. An SEM image of a flax fiber is shown in Fig. 4 Baley, 2002] which exhibits a polygonal shape. Moreover, the cross-section of plant fibers is usually not uniform along the longitudinal direction Charlet et al., 2010b. 


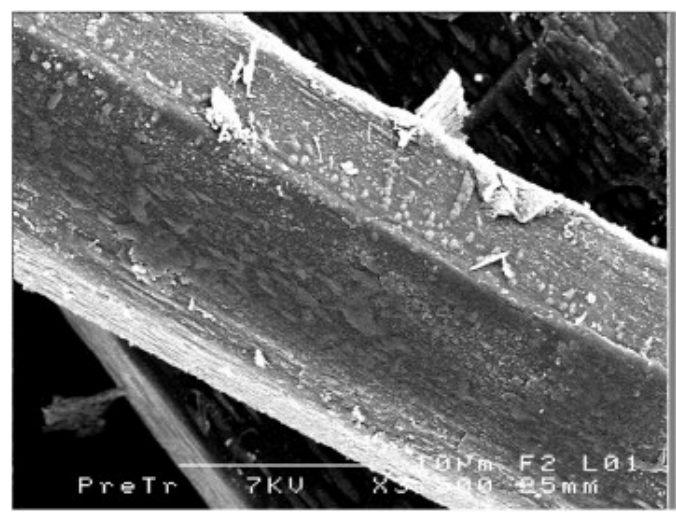

Fig. 4. Example of polygonal section in a flax fiber [Baley, 2002].

The irregular and nonuniform cross-section of plant fiber adds to the difficulty in the accurate measurement of their strength.

Figures 24 illustrate the microstructure of flax fibers. Some of the features of flax fibers summarized in this section are common to other bast fibers. For instance, Shahzad 2012] reported that the average hemp fiber length was found to be $8.46 \mathrm{~mm}$ with a range of 1-34 mm while Akil et al. 2011] also used a multi-cell wall model to represent the structure of a kenaf fiber. The limited length, complex multi-cell wall structure and irregular cross-sections of plant fibers often add to the difficulty in the prediction of mechanical properties of their composites.

\section{Mechanical Properties of Plant Fibers and Their Composites}

The properties of common natural plant fibers are summarized in Table1 in comparison with that of other structural material including high-strength synthetic fibers and stainless steel. It should be emphasized that the plant fibers listed in Table 1 are relatively high-strength fibers in the entire family of natural fibers. The strength of carbon fiber is almost three times of that of flax fibers. Glass fiber has higher strength than the natural fibers listed in Table 1 However, the specific strength of flax fibers is relatively close to that of glass fibers. Both the strength and specific strength of flax fiber is higher than that of stainless steel.

The strength of natural fiber composites is relatively lower than carbon and glass fiber reinforced composites. This often limits their possible applications on primary structures. However, this may be overcome as technological advances. Hybridization is a potential while promising technique for such purpose Arbelaiz et al., 2005a. Hybrid composite materials are a combination of more than one type of fiber in the same matrix Dhakal et al., 2013; Saidane et al., 2016]. Dhakal et al. 2013 studied flax/carbon fiber hybrid composites using prepreg materials. It is not difficult to conceive that the mechanical properties (e.g., strength and flexural 
Table 1. Properties of several common natural plant fibers in comparison with carbon fiber, glass fiber and common matrix material.

\begin{tabular}{|c|c|c|c|c|c|}
\hline Material & $\begin{array}{l}\text { Density } \\
\left(\mathrm{kg} / \mathrm{m}^{3}\right)\end{array}$ & $\begin{array}{l}\text { Strength } \\
(\mathrm{MPa})\end{array}$ & $\begin{array}{l}\text { Modulus } \\
(\mathrm{GPa})\end{array}$ & $\begin{array}{l}\text { Specific strength } \\
\left(\mathrm{MPa}^{*} \mathrm{~m}^{3} / \mathrm{kg}\right)\end{array}$ & Reference \\
\hline Flax fiber & 1500 & $733-1454$ & $45.6-71.7$ & 0.729 & Yan et al. [2014] \\
\hline Jute fiber & 1390 & $223-499$ & 26.25 & 0.260 & $\frac{\text { Defoirdt et al. }}{[2010]}$ \\
\hline Hemp fiber & 1480 & 550-900 & 70 & 0.490 & $\frac{\text { Ahmad et al. }}{[2015]}$ \\
\hline Kenaf fiber & 1450 & 930 & 53 & 0.641 & $\frac{\text { Ahmad et al. }}{[2015]}$ \\
\hline Sisal fiber & 1500 & $511-635$ & $9.4-22$ & 0.382 & $\begin{array}{l}\text { Holbery and } \\
\text { Houston }[2006]\end{array}$ \\
\hline Cotton & $1500-1600$ & 400 & $5.5-12.6$ & 0.258 & $\frac{\text { Wambua et al. }}{\text { [2003] }}$ \\
\hline E-glass fiber & 2500 & $2000-3000$ & 70 & 1 & $\frac{\text { Pickering et al. }}{[2016]}$ \\
\hline Carbon fiber & 1800 & $3400-4900$ & $230-245$ & 2.306 & $\begin{array}{l}\text { Cao et al. }[2011] ; \\
\text { Pil et al. }[2016]\end{array}$ \\
\hline Polypropylene & 900 & $36.1 \pm 0.1$ & $1.7 \pm 0.03$ & 0.040 & $\begin{array}{l}\text { Le Duigou and } \\
\text { Baley[2014]; } \\
\text { Kellersztein } \\
\text { and Dotan [2016] }\end{array}$ \\
\hline Epoxy & 1250 & $83.73 \pm 1.15$ & $3.30 \pm 0.07$ & 0.067 & Gao et al. [2012] \\
\hline Stainless steel & 7902 & 611-878 & 180-215 & 0.094 & $\begin{array}{l}\text { Rasmussen [2003]; } \\
\text { Young [2008] }\end{array}$ \\
\hline
\end{tabular}

properties) will increase due to the addition of high-strength carbon fibers. Another important benefit of hybridization is that the amount of moisture gain after exposure to humid environment would reduce after incorporating carbon fiber into flax fiber/epoxy composites. The advantages, disadvantages, manufacturing related issues of hybridization remain unsolved and this will be a promising field for future research. Davoodi et al. 2011] performed geometric optimizations for concept selection of car bumper beam with developed hybrid bio-composite material which proved that concept design was also an option to increase the performance of natural fiber composite structures.

Typical force/displacement curves for flax fibers under tensile loading are plotted in Fig. 5 in comparison with that of glass fibers. Glass fibers exhibited a linear elastic behavior under monotonic tensile loading. Flax fibers, however, showed a different response. The tensile stress/strain curves for carbon fiber and glass fiber were linear until the fiber failed in a brittle manner. However, plant fibers such as flax and ramie fibers exhibited a nonlinear trend on their stress/strain curves Charlet et al., 2009. As illustrated in Fig. 3 there is a small angle between the micro-fibrils and the axis of the fiber. The micro-fibrillar angle of the secondary cell wall was reported to be around $10^{\circ}$. The progressive realignment of the cellulosic micro-fibrils with the fiber axis under tensile loading accounted for such departure from linearity. The complex, nonlinear behavior of single plant fibers translates into their composites Rubio-López et al., 2016; Pupure et al., 2016. The Young's 


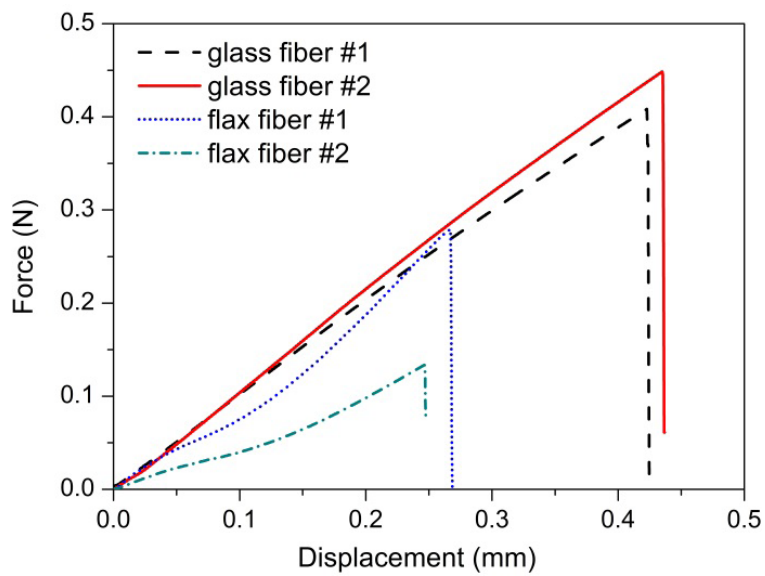

Fig. 5. Typical force/displacement curves for glass fiber and flax fiber under tensile loading.

modulus or stiffness measured at different magnitudes of strain before failure during monotonic tensile tests on graphite or glass fiber is normally constant or varies fairly little. In contrast, in a recent study by Shah [2016], it was observed that for plant fiber reinforced composites, the stiffness decreased dramatically at the early stage of monotonic tensile loading. Thereafter, in general, the stiffness remained fairly constant up to their failure strain.

Polymer matrix composites, such as carbon fiber and glass fiber reinforced composites are known to be susceptible to the combined hygrothermal effects due to the hybrid nature of their microstructure and the polymer matrix which absorbs moisture and suffers from property degradation subsequently Zhong and Joshi, 2015, 2016]. Environmental durability issue is even more critical for natural plant fiber composites since besides the polymer matrix plant fibers also absorb moisture when exposed to humid environments. It is a common practice to dry the natural fiber preforms prior to fiber impregnation with polymers in order to remove the moisture stored in these natural fibers. The hygrothermal aging effects on natural fiber composites have attracted attention from researchers recently. Dhakal et al. 2007] explored the effect of water absorption on the mechanical properties of hemp fiber reinforced unsaturated polyester composites. The percentage of moisture uptake in natural fiber composites would increase as their fiber volume fraction increased due to high cellulose content. Moisture uptake at low or room temperature showed Fickian behavior, while at boiling temperature, a non-Fickian behavior was observed. The deviation from Fickian water uptake behavior at $100^{\circ} \mathrm{C}$ is attributed to the development of micro cracks in the composites. Debonding of the fiber and the matrix was observed. The water molecules were actively attacking the interface, resulting in fiber/matrix interface deterioration. Decrease in both tensile and flexural properties was observed after moisture absorption. Similar findings were reported by Arbelaiz et al. [2005b]. 
Table 2. Properties of flax fibers as reported by different researchers.

\begin{tabular}{lccccc}
\hline Authors & $\begin{array}{c}\text { Diameter } \\
(\mu \mathrm{m})\end{array}$ & $\begin{array}{c}\text { Density } \\
\left(\mathrm{kg} / \mathrm{m}^{3}\right)\end{array}$ & $\begin{array}{c}\text { Strength } \\
(\mathrm{MPa})\end{array}$ & $\begin{array}{c}\text { Modulus } \\
(\mathrm{GPa})\end{array}$ & $\begin{array}{c}\text { Elongation } \\
(\%)\end{array}$ \\
\hline Lefeuvre et al. $[2014]$ & $15.1( \pm 3.4)$ & - & $1031( \pm 392)$ & $55.3( \pm 13.0)$ & $2.0( \pm 0.6)$ \\
Baley [2002] & $23( \pm 5.7)$ & 1530 & $1339( \pm 486)$ & $54.08( \pm 15.13)$ & $3.27( \pm 0.84)$ \\
Davies and Bruce [1998] & - & - & $621( \pm 295)$ & $51.7( \pm 18.2)$ & $1.33( \pm 0.56)$ \\
Oksman et al. [2003] & - & 1500 & $600-1000$ & - & $1-2$ \\
Khot et al. [2001] & - & 1500 & 1100 & 100 & - \\
Yan et al. [2014] & $12.9-21.5$ & 1500 & $733-1454$ & $45.6-71.7$ & $1.6-2.3$ \\
\hline \hline
\end{tabular}

One of the important features of natural plant fibers and their composites is the relatively high variation in their strength and modulus. Properties of flax fibers reported by several researchers are summarized in Table 2 Scattering in the reported data is easily observed. The distribution of strength and modulus of natural plant fibers therefore became an interesting topic. A review on this subjected was carried out by Summerscales et al. [2013]. Andersons et al. [2005] performed tensile tests on single elementary flax fibers. Weibull distribution was used to fit experimentally measured data on tensile strength, modulus and failure strain. Marked scattering in the measured strength, modulus and elongation at failure was observed. While the modulus was slightly affected by fiber length, the strength depended largely on gauge length. Bos et al. 2002] reported compressive and tensile properties of flax fibers. Both clamping length during the test and decortication technique would affect the final measured strength values. Similar work has been done by Virk et al. 2011. who studied the tensile properties of jute fibers and characterized the variation in strength and failure strain using Weibull statistics based on a maximum likelihood estimate.

The mechanical properties of glass fibers are sensitive to surface flaws while the static properties of the carbon fiber are also not uniform and exhibit certain extent of deviation. For plant fibers, the scattering in tensile strength is even more evident due to several reasons. Take flax fibers for instance. Common factors that will cause the variation in material properties include the variety of flax plant, geographical area where these flax plants are planted, local climate conditions such as pluviometry and sunlight intensity, agronomical practices, and maturity of plants at the time of pulling out as well as the fiber processing techniques. The surface treatment techniques of different manufacturers partially explain the variation in the quality of natural plant fibers Tayfun et al., 2016; George et al., 2016]. The density and severity of kink bands on natural plant fibers also affect the measured strength and lead to variation among the testing results.

All these factors co-exist and lead to the variation in the properties of natural plant fibers. Comprehensive studies on the effects of individual factors are expected to be difficult to implement. Lefeuvre et al. 2014] presented an interesting experimental work on the reproducibility of the tensile properties of elementary flax fibers. The variation in tensile properties of one textile flax variety (Marylin) grown in the 
same geographical area over four years (2009-2012) was analyzed and compared with that of the glass fibers. It was found that tensile properties of elementary flax fibers were reproducible despite drought or an excess of water during the vegetative period. The magnitude of strength and strain at break of commercial glass fibers were found to be as scattered as the flax fibers ones.

The high variability in strength of natural fibers is a common concern. However, such high variability is to some extent overestimated. The variation in strength and failure strain of technical fibers was reported by Virk et al. [2010] who tested 785 jute technical fibers. It was interesting that the coefficient of variation for failure strain was consistently smaller than that for strength. Calculation of strength inevitably involved the cross-sectional area of the fiber, which was difficult to accurately characterize for natural fibers. However, the measurement of strain did not rely on cross-sectional area. Therefore, the variability in strength could partially be attributed to the difficulty in obtaining the accurate cross-sectional area.

Fortunately, such variability in properties changes at different scales. Blanchard et al. 2016] tested the strength of flax fiber/epoxy composites at three different scales, i.e., yarn level, cloth level and laminate level. The coefficients of variation for breaking force at yarn level and cloth level were $20.3 \%$ and $4.0 \%$, respectively. The coefficient of variation decreased substantially from yarn level to cloth level. It was reported that the coefficient of variation for strength of the laminate level was $7.89 \%$, which was comparable to that of glass fiber reinforced composites. The results of this study proved that though there is relatively high variability in the strength of single natural fiber, the variability in the properties of a macro natural fiber composite might be limited.

Ku et al. 2011] proposed a review on the tensile properties of natural fiber reinforced polymer composites. The tensile strength and modulus would increase with the weight fraction of fibers in the composites. In particular, the strength of the composites relies largely on the fiber/matrix interfacial bonding. However, poor adhesion between the matrix and natural fibers was reported by Bax and Müssig 2008. Therefore, the fiber/matrix interface is a popular research topic in the last decade. Various surface treatment techniques were developed to improve the interfacial properties Kalia et al., 2009]. Zafeiropoulos et al. 2002a, 2002b] applied two surface treatment techniques, i.e., acetylation and stearation, to flax fiber/polypropylene composite materials. The interface of flax fiber/polypropylene composites was assessed by means of fragmentation tests. Improvement of the stress transfer efficiency at the interface was achieved.

Both analytical and experimental works on short fiber reinforced composites were reported. Effects of fiber length, fiber diameter, length-to-diameter ratio and fiber volume fraction on the stiffness and strength of short natural fiber composites are generally concerned. Garkhail et al. [2000] experimentally did tensile and Charpy impact tests on flax fiber mat reinforced polypropylene composites and compared relevant results with micromechanical predictions. The fiber volume fraction 
was found to significantly affect the properties of random flax fiber composites. However, no real experimental evidence for the anticipated increase in mechanical performance with increasing fiber length was found.

\section{Sound and Vibration Damping Aspects of Plant Fiber Composites}

Carbon fibers and glass fibers are developed and manufactured mainly for their high strength and high strength-to-weight ratios. However, natural fibers and their composites can be used as multi-functional materials besides their high strengthto-weight ratios. Sound in an object (e.g., a commercial passenger car) is generally propagated through the air (airborne sound), and by vibrations of the body (structural sound). In the science of acoustical control, two classes of acoustical treatments can be used to address airborne noise, namely barriers and absorbers while for structure-borne noise, isolators and dampers are two possible treatments Parikh et al., 2006. Natural fibers and their composites are potential sound absorbers and noise reducers. Compared to synthetic fibers such as carbon and glass fibers composites, plant fibers (e.g., ramie, flax and jute fibers) and their composites have superior capability of noise reduction. Sargianis et al. [2013] reported the acoustic and damping properties of sandwich structures with natural fiber composite face-sheets. As compared with sandwiches with carbon fiber composite facesheets, natural material sandwich structures exhibited better acoustic performance (increased coincidence frequency) and slightly lower bending stiffness. The multiscale and hollow lumen structures of natural fibers contributed to their high sound absorption performance Yang and Li, 2012. Multi-functional composite materials can be made by natural fibers so that both the mechanical and acoustical functions can be achieved.

The noise reduction performance of various natural plant fibers has been studied. These include coir fiber Nor et al., 2010], bamboo fibers Huda et al., 2012], cotton fiber Mueller and Krobjilowski, 2003, flax fibers Haij et al., 2011, ramie fibers Chen et al., 2010], jute fibers [Fatima and Mohanty, 2011], etc. Thilagavathi et al. 2010 reported experimental results on bamboo, banana and jute fiber nonwovens as renewable alternatives for automotive interiors to reduce noise. It is interesting to find out that bamboo/polypropylene nonwoven composites have better sound absorption property than the other fibers. The same finding has been confirmed by Huda et al. [2012]. More experimental characterization work is to be carried out to fully explore the potential advantages of natural plant fibers for acoustic applications.

In the meantime, there are sound absorbing models which aim to describe the characteristic wave impedance and the sound propagation constant using the basic physical properties of the materials, such as the porosity and the airflow resistance Berardi and Iannace, 2015]. The first model to be mentioned is the Delany-Bazley model which was defined by using a best-fitting approach to a large amount of 
experimental data Delany and Bazley, 1970]:

$$
\begin{aligned}
& z_{c}=\rho_{0} c\left[1+0.0571\left(\frac{\rho_{0} f}{\sigma}\right)^{-0.754}-j 0.087\left(\frac{\rho_{0} f}{\sigma}\right)^{-0.732}\right], \\
& k_{c}=\omega / c\left[1+0.0978\left(\frac{\rho_{0} f}{\sigma}\right)^{-0.7}-j 0.189\left(\frac{\rho_{0} f}{\sigma}\right)^{-0.595}\right],
\end{aligned}
$$

where $z_{c}$ is the characteristic impedance; $k_{c}$ is the propagation constant; $\rho_{0}$ and " $c$ " are the density and speed of air media, respectively; " $f$ " and $\omega(=2 \pi f)$ are the frequency and angular frequency, respectively; $j=\sqrt{-1}$, Rwawiire et al., 2017]; $\sigma$, which is the flow resistivity, is calculated as follows:

$$
\sigma=\frac{6.8 \eta(1-\varepsilon)^{1.296}}{a^{2} \varepsilon^{3}},
$$

where $\eta$ is the viscosity of air; " $a$ " is the radius of the fibers and $\varepsilon$ is the porosity of the fibrous material. Garai and Pompoli proposed similar formulas to those of the Delany-Bazley model, but with different coefficients [Garai and Pompoli, 2005]:

$$
\begin{aligned}
& z_{c}=\rho_{0} c\left[1+0.078\left(\frac{\rho_{0} f}{\sigma}\right)^{-0.623}-j 0.074\left(\frac{\rho_{0} f}{\sigma}\right)^{-0.66}\right], \\
& k_{c}=\omega / c\left[1+0.121\left(\frac{\rho_{0} f}{\sigma}\right)^{-0.53}-j 0.159\left(\frac{\rho_{0} f}{\sigma}\right)^{-0.571}\right] .
\end{aligned}
$$

Both the Delany-Bazley model and Garai-Pompoli model are empirical model. These two models differ only in the values of the constants. The Delany-Bazley model was obtained based on measurements on fibers with diameters between $1 \mu \mathrm{m}$ and $10 \mu \mathrm{m}$, whereas Garai and Pompoli studied polyester fiber materials with diameters ranging from approximately $20 \mu \mathrm{m}$ to $50 \mu \mathrm{m}$ to obtain the Garai-Pompoli model. The Garai-Pompoli equations have sometimes proved to be more accurate than the Delany-Bazley model for the study of natural fibers, since these fibers show diameters and density closer to those considered by Garai and Pompoli [Berardi and Iannace, 2015].

Yang and Li 2012] has applied both models to calculate the sound absorption performance of jute fibers. The general trend of the theoretical calculations was validated and reflected by experimental measurements. Johnson-Allard rigid frame model is another analytical model that is applicable to natural fiber composites. This model involves parameters such as bulk density, fiber diameter and thickness. Nor et al. [2010] studied the effect of different factors on the sound absorption behavior of coir fiber natural materials. The effects of bulk density, fiber diameter and samples thickness on sound absorption were successfully studied. It was found that layer thickness and fiber diameter had a significant effect on the absorption, whereas bulk density did not have any considerable effect. Increasing coir fiber layer thickness increased the sound absorption. With the 
reduction of fiber diameter significant enhancement in low frequency absorption was observed. The practical meaning of this study is that the sound absorption performance of natural fiber composites can be designed and varied by modifying the corresponding parameters. For instance, by using fibers of smaller diameters, approximately the same sound absorption was achieved by thinner coir fiber samples.

Another advantage of natural fibers over carbon and glass fibers is their better damping properties Daoud et al., 2016. . Damping alleviates the relative motions in an object and converts kinetic energy into heat or other disposable energy types. It has been experimentally proven by Duc et al. [2014] that the loss factor which was measured by temperature sweep tests of flax fiber composites was significantly higher than that of glass and carbon fiber composites. In the study by Duc et al. 2014], the matrix resin, fiber volume fraction and fiber architecture were kept the same in order to compare the vibration damping properties of natural fibers with that of synthetic fibers. The addition of unidirectional flax fiber tape to epoxy led to an approximately $100 \%$ increase in loss factor with respect to both the matrix resin and glass fiber reinforced epoxy. The good vibration damping properties of natural fibers make them promising candidate materials for sporting goods such as tennis racket and bicycle frames.

\section{Review of Techniques for Simulation and Existing Challenges}

Compared to carbon and glass fiber reinforced composites, numerical works on the natural fiber composites are scarcely reported in the literature. The first step of finite element analysis is to create the geometry of the structure and assign material properties [Ni and Wei, 2016]. The finite element analysis on the mechanical properties of natural fibers composites is a straightforward process during which certain failure criteria would be used to define the initiation and propagation of failure. As seen in Fig. 5, the tensile stress/strain behavior of the plant fiber is different from that of the glass fiber. However, no failure criteria are proposed specifically for natural fibers. Instead, failure criteria developed for high-strength synthetic fibers were frequently exploited for the analysis of natural fiber composites. These failure criteria are able to predict the ultimate strength of natural fiber composites. However, the unique features such as the nonlinear tensile response of natural fibers and their composites would be ignored. Misri et al. [2015] used Tsai-Wu failure criterion during the simulation of the torsional behavior of a kenaf / unsaturated polyester composite hollow shaft which was fabricated via filament winding. Kenaf/unsaturated polyester composite hollow shaft with and without aluminum tubes were fabricated. Their torsional behavior was predicted using commercial finite element software Abaqus with Tsai-Wu failure criterion to define the failure. Both experimental and numerical results proved that a winding angle of $45^{\circ}$ resulted in higher maximum static torsion capacity of the composites than $90^{\circ}$ while the presence of aluminum tubes enhanced the torsion property significantly. 


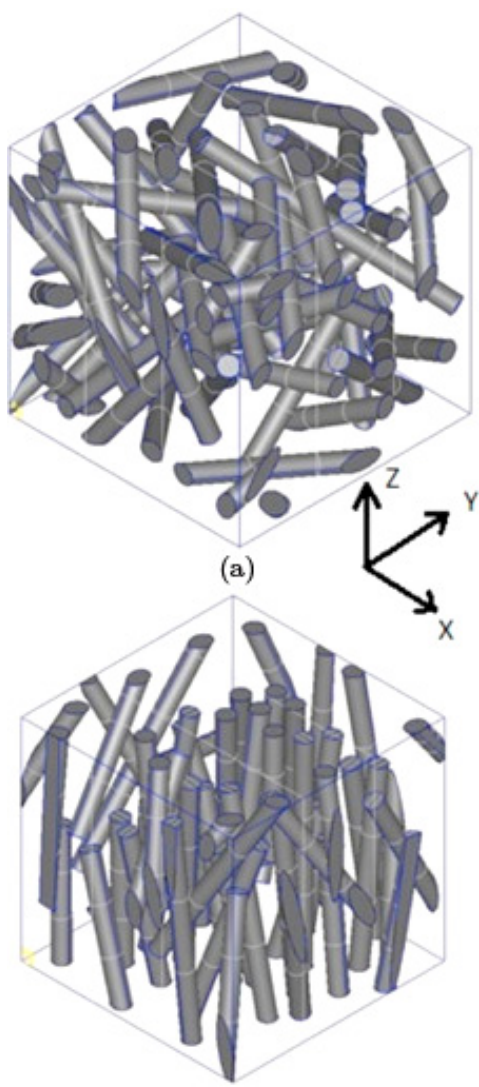

(c)

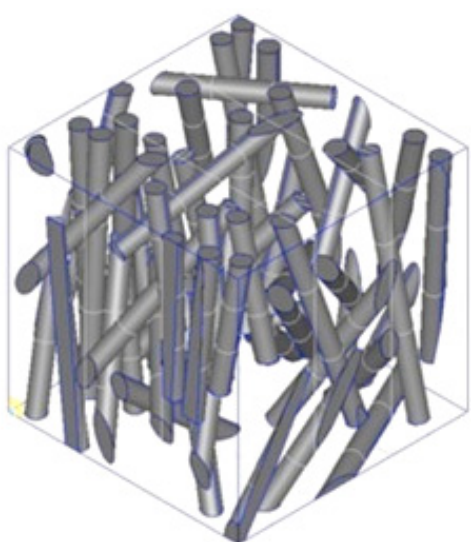

(b)

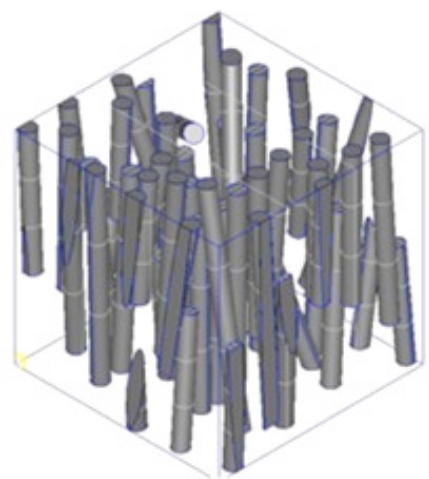

(d)

Fig. 6. Micro-scale representative volume elements of short flax fibers/polypropylene composites with different fiber orientation coefficients: (a) orientation coefficient 0.32 ; (b) orientation coefficient 0.59 ; (c) orientation coefficient 0.72 ; (d) orientation coefficient 0.84 [Sliseris et al., 2016].

Sliseris et al. 2016] defined a micro-scale representative volume element (RVE) for short flax fiber reinforced composites using algorithm taking into consideration fiber bundles, fibers and defects on fibers (Fig. 6). Micro-scale RVEs with short flax fibers of different fiber orientations, length-to-diameter rations and randomly dispersed defects were created by using a python script within Salome-Meca 2015 software. The elastic properties (e.g., tensile modulus of flax fabric/epoxy composites) as well as the tensile stress/strain curves were predicted and good agreement with experimental observations was achieved. The nonlinear tensile stress-strain behavior of the short fiber and fiber fabric reinforced polymer composites was successfully captured. Prediction of the properties of short fiber reinforced composites via micro-scale RVEs is an efficient and reliable technique. Similar micro-scale model was developed by Yim et al. [2015] for the prediction of the compressive properties of metal matrix composites with short fiber reinforcements and particles. However, 
it should be mentioned that in the micro-scale model developed by Sliseris et al. 2016] the flax fiber was treated as isotropic material with linear elastic behavior. However, as discussed in Sec. 2 the multi-cell wall structure of flax fiber clearly demonstrated that these natural fibers are not isotropic material. Similar approximation was applied by Nirbhay et al. [2015] in the finite element analysis of multipanel structures made of treated coir and jute fiber reinforced hybrid composites. The hybrid composites were also treated as isotropic material with uniform Young's modulus and Poisson's ratio.

Progressive damage analysis is a popular topic for the mechanical property prediction of composites Lampeas and Fotopoulos, 2015]. Typical process of progressive failure analysis is illustrated in Fig. 7. There is a large body of literature on progressive damage analysis in composites, much of which employs damage mechanics and material stiffness degradation methods [Tay et al., 2008]. As seen in Fig. 7 . during each iteration or load increment, the stress state of the structure is computed and the resulting damage state is defined by certain failure criteria. Based on the extent of damage, the properties of the material will be degraded. Subsequently, a new stiffness matrix will be obtained for the next iteration until eventually the structure fails. The key element of progressive damage analysis is the

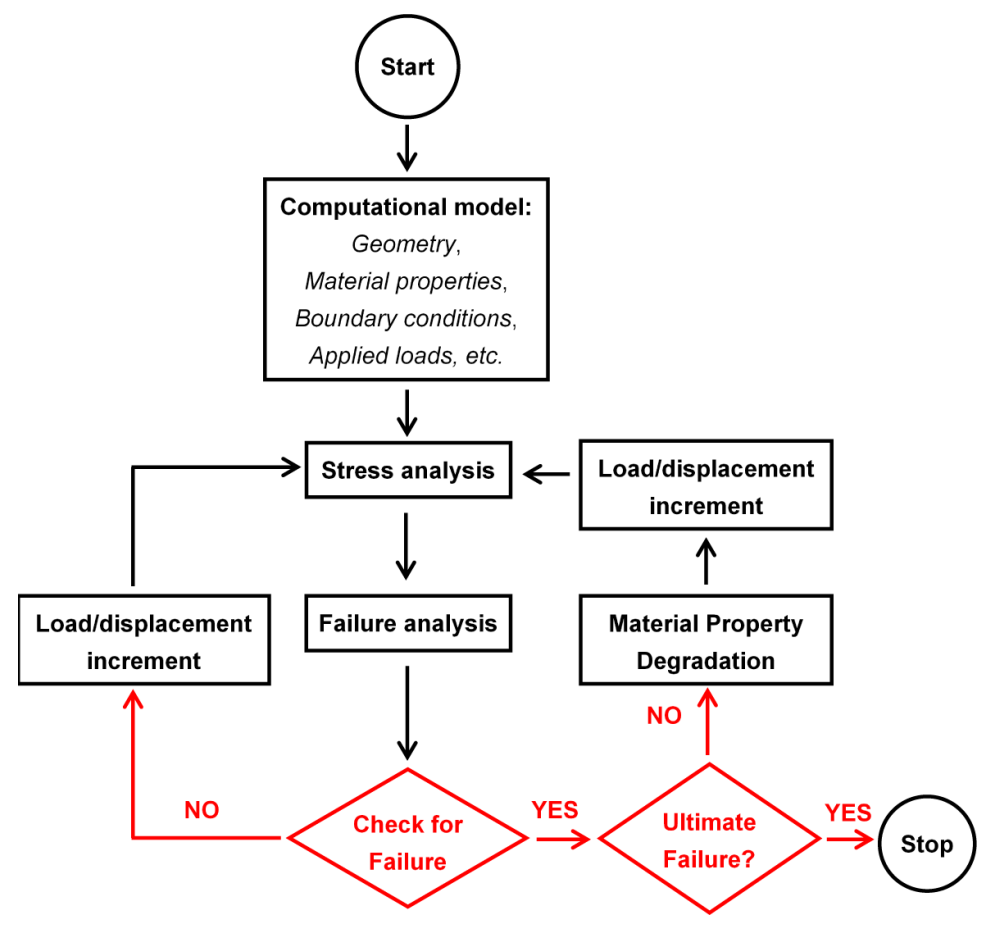

Fig. 7. Flowchart of progressive failure analysis Turan and Pekbey, 2014]. 
damage model which defines the failure and governs the subsequent stiffness degradation. USDFLD and UMAT interface of ABAQUS solver are effective techniques for the modeling of the progressive damage in composite materials Liu et al., 2016; Olmedo and Santiuste, 2012. The constitutive models, failure criteria and material degradation scheme can be executed using these interfaces.

Progressive damage analysis carried out on carbon and glass fiber composites has provided results of acceptable accuracy Belingardi et al., 2016; Zhang and Zhao, 2011. This method can also be applied to composites reinforced by natural fibers for property prediction. Panamoottil et al. [2016] developed an anisotropic continuum damage model for the prediction of the tensile response of flax/polypropylene composites. Damages in the dogbone coupon under tensile loading along different directions were quantified using optical microscope images. A damage tensor was subsequently built, based on which, a material damage model was implemented in ABAQUS using the user defined material (UMAT) option. The failure strength predicted by this model was within $3.1 \%$ of the experimental value. This study showed that combining a geometric model closely incorporating the actual geometry of a fabric composite with an experimentally determined material degradation model can yield good predictions of the mechanical behavior of the composite. However, similar work carried out on natural plant fiber composites are insufficiently reported in the literature.

Analytical models proposed specifically for natural plant fiber composites are also rarely reported in the literature. Models developed for high-strength brittle fibers such as the carbon and glass fiber can in certain cases be applied to natural fibers depending on the characteristics of the fiber. Müssig et al. [2006] used the micromechanical model developed by $\mathrm{Cox}$ 1952] to calculate the elastic modulus of short natural fiber reinforced polymers by introducing fiber length efficiency factor $\eta_{l}$ and fiber orientation factor $\eta_{0}$ :

$$
E_{C}=\eta_{l} \cdot \eta_{0} \cdot E_{f} \cdot \varphi_{f}+E_{m} \cdot\left(1-\varphi_{f}\right),
$$

where, $E_{C}$ stands for the modulus of the composites, $E_{f}$ stands for the modulus of the fiber, $\varphi_{f}$ is fiber volume fraction and $E_{m}$ is modulus of the matrix resin. Good agreement between prediction and experimental observations was achieved for ramie fiber reinforced composites. However, the elasticity modulus calculated for cotton and lyocell reinforced composites were much too low compared with the experimentally measured values. It is known that the micromechanical model expressed in Eq. (6) predicted good results for glass fiber reinforced composites Thomason and Vlug, 1996. The tensile-elongation-behavior of glass and ramie fibers is very similar. However, cotton and lyocell fibers have different characteristics under tensile loading as compared with the glass fiber. The author proposed that the accuracy of the micromechanical model depends on the characteristics of the natural fibers.

Similar work has been reported by Andersons et al. [2006] who applied analytical models to short flax fiber composites to predict their modulus and strength. 
Equation (6) was selected to predict the modulus of flax fiber composites, whereas the strength of the composites $\sigma_{C}$ was predicted using a rule-of-mixtures model which was developed from the following analytical model:

$$
\sigma_{C}=\eta_{l} \cdot \eta_{0} \cdot \sigma_{f} \cdot \nu_{f}+\sigma_{m} \cdot\left(1-\nu_{f}\right),
$$

where $\sigma_{f}$ and $\sigma_{m}$ denote the axial stress acting in the fibers and matrix, respectively, and $\nu_{f}$ is the fiber volume fraction in the composite. The stiffness was predicted with acceptable accuracy. However, the sensitivity of the rule-of-mixtures model of strength to material properties apparently depended on the relative ineffective fiber length. For relatively long-fiber flax fiber mat composites, the sensitivity is low and more sophisticated strength models should be applied.

Wood fibers are also a very important category of natural fibers. Neagu et al. 2006. presented a quantitative analytical-experimental method to determine the stiffness properties of the wood fibers from macroscopic tensile tests of composites. This method included three steps: (i) characterization of the composite, including measurement of the Young's modulus, fiber volume fraction and fiber orientation distribution; (ii) modeling of the Young's modulus of the composite in terms of the elastic constants of the fibers, fiber volume fraction and fiber orientation using laminate analogy and a micromechanical model, and (iii) inverse calculation to predict the stiffness of the fibers from composite stiffness. Using this method, from the tensile test results of the composites, the contributing Young's moduli of the fibers in the longitudinal direction are back-calculated and summarized.

Similar inverse calculation was conducted by Modniks et al. 2012. to predict the interfacial shear strength (IFSS) of short fiber reinforced composite. This inverse calculation was based on Eq. (7) with that assumption that the fiber length efficiency factor $\eta_{l}$ depends on fiber lengths and IFSS $\tau$. Equation (7) was fitted to the experimental tension curves of short-flax-fiber reinforced polypropylene to evaluate the IFSS and the fiber orientation factor of the composite. The results of calculation revealed that the addition of an adhesion modifying agent, maleic anhydride-grafted $\mathrm{PP}$, led to an increase in the IFSS by more than $50 \%$.

Kebir and Ayad 2014] proposed a finite element procedure for the calculation of Young's modulus and Poisson's ratio of short hemp fiber reinforced polypropylene composites. In this model, the fiber was meshed using 1-dimension 2-node truss elements while the resin was meshed using 2-dimension 3-node constant strain triangle elements. Parametric study for the size of RVEs and number of elements was carried out and the Young's modulus predicted was in a reasonable range. However, limitations also existed. Firstly, the hemp fiber was treated as isotropic material. Secondly, the size of the short fibers was uniform rather than stochastic size for individual fibers. Thirdly, the 3-dimension problem was simplified to a 2-dimension problem. For carbon and glass fiber, plenty of experimental data concerning their elastic properties were reported in the literature. However, such data on natural fibers are not available. This is the reason why natural fibers were treated as isotropic material in these reported numerical and analytical models. Sufficient attention should be paid 
on the systematic characterization of the mechanical properties of common natural fibers to fill the gap.

Prediction of the various behaviors of plant fiber composites is still a relatively new topic. There is a lack of relevant models specifically developed for natural plant fiber composites. Existing analytical models and numerical techniques developed for synthetic fiber reinforced composites might be applicable to plant fiber composites on a case-by-case basis. However, plant fibers and their composites have different characteristics which should be carefully considered prior to applying existing models to them. There are also existing technical challenges that should receive special attention.

As summarized in Sec. 2, an elementary plant fiber itself is built up by several cell wall layers consisting of numerous micro-fibrils. During the simulation process, a plant fiber should be treated at least as transversely isotropic material rather than isotropic. For the modeling of transversely isotropic materials, the strength and moduli along and transverse to the fiber direction are to be obtained Li et al., 2015]. Nobeen et al. [2016] and Wang et al. 2016a. predicted the strength of braided composites reinforced by carbon fibers which were modeled as transversely isotropic material. Elastic constants including $E_{11}, E_{22}, G_{12}, G_{23}, \nu_{12}$ and $\nu_{23}$, strength values including longitudinal and transverse tensile strength were basic inputs during simulation. However, for natural plant fibers, such as the flax fiber, complete sets of such basic data are not available to the best of the authors' knowledge. Longitudinal tensile strength and modulus of flax fibers are available Andersons et al., 2009; Zeng et al., 2015; Lamon et al., 2016]. However, complete set of properties of natural plant fibers is not reported yet. Systematic experimental characterization work needs to be carried out to obtain these properties which will definitely benefit the subsequent analytical and numerical work.

The second challenge is resulted from the geometry of natural plant fibers. As mentioned above, the length of natural plant fibers is limited. The plant fibers in the commercial form of roving, tape, fabric and prepregs are usually discontinuous (although these fibers are not necessarily defined as short fiber). This needs to be reflected in the predictive model for the mechanical properties of natural fiber composites [Andersons et al., 2011. Andersons et al. 2011] proposed a statistical model to calculate the strength of unidirectional (UD) flax fiber composites considering the discontinuity of flax fibers. The clusters of adjacent fiber discontinuities in the composite were treated as notches (marked in black in Fig. 8(a)). This statistical model was built by incorporating the probabilistic distribution function of fiber strength $\sigma_{f}$ into the following equation:

$$
\sigma_{C}=\sigma_{f} \cdot \nu_{f}+\sigma_{m}\left(1-\nu_{f}\right)
$$

where $\sigma_{C}$ and $\sigma_{m}$ are the strength of the composites and the matrix resin, respectively, and $\nu_{f}$ stands for the fiber volume fraction. Good agreement of the theoretical average strength with the test results was yielded when assuming a $4 \times 4$ adjacent fiber discontinuities (Fig. $8(b)$ ). Fiber discontinuity distribution is apparently 


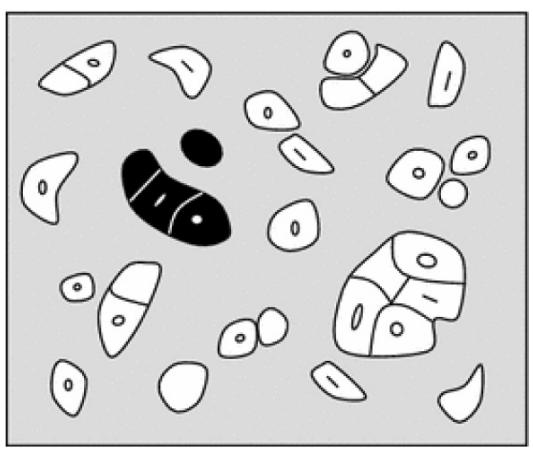

(a)

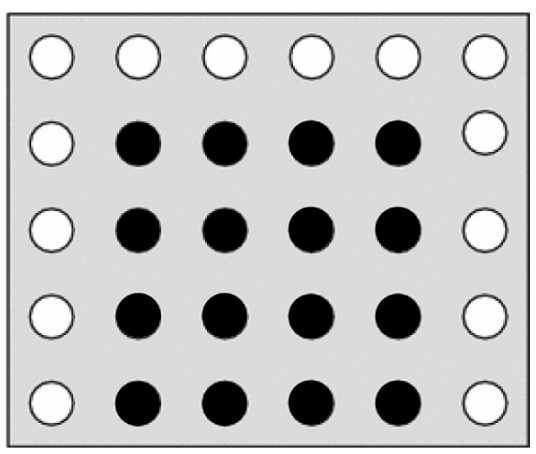

(b)

Fig. 8. Cross-section of UD flax fiber composite: (a) a cross-section of UD flax fiber composite containing elementary and technical fibers; (b) an idealized model composite with regularly arranged elementary flax fibers of the same fiber volume fraction in which discontinuous adjacent fibers forming a cluster $(4 \times 4)$ are marked in black Andersons et al., 2011].

random and such fixed size will not be always guaranteed. Therefore, this model is only accurate under certain circumstances. During finite element analysis, the discontinuity should be taken into consideration for the accuracy and reliability of the results. This becomes the second challenges for natural plant fiber composites.

The third challenge during the prediction of the mechanical properties of natural plant fiber composites is the high variability in their properties. Using Weibull distribution to account for the distribution of strength is a common practice in many numerical and analytical models [Wang et al., 2016b; Andersons and Joffe, 2011]. However, when using commercial finite element software to predict the properties of natural plant fiber composites, it is difficult to apply statistical model and using an average value when assigning material property seems inevitable. Proper consideration of the high variability in the properties is another challenge for the prediction of the property and failure of natural plant fiber composites.

As mentioned above, natural plant fibers have lower strength and absorb moisture when exposed to humid environment Pan and Zhong, 2015b; Thwe and Liao, 2002]. Using combinations of natural and synthetic fibers (hybridization) in one composite material is a promising solution for many engineering applications Ashworth et al., 2016; Flynn et al., 2016. The mechanical properties of hybrid short fiber composites can be evaluated using the Rule of Hybrid Mixtures equation, which is widely used to predict the strength and modulus of hybrid composites Venkateshwaran et al., 2012; Fu et al., 2002; Mirbagheri et al., 2007. The Rule of Hybrid Mixtures for the calculation of the Young's modulus $E_{C}$ of the hybrid fiber composite is expressed as:

$$
E_{C}=E_{C}^{(10} f(1)+E_{C}^{[2]} f^{(2]},
$$

where the superscript " 1 and 2" represents the physical quantities of short natural fiber composite (composite 1) and short synthetic fiber composite (composite 2), 
respectively. The moduli $E_{C}^{\frac{1}{1}}$ and $E_{C}^{\sqrt[2]{2}}$ are the Young's modulus of composites 1 and 2. $f^{11}$ and $f^{2}$ are relative fiber volume fractions. However, prediction of the mechanical properties of natural fiber/synthetic fiber hybrid composites is still a new and challenging topic of research.

Prediction of the moisture absorption related phenomena in plant fiber composites is another existing challenge. Experimental work carried out to study the strength of composites after hygrothermal ageing and simulation work towards the moisture diffusion phenomenon in natural fiber composites was reported by Toubal et al. [2016]. It was found that moisture absorption in short hemp fiber reinforced polypropylene composites did not follow Fick's law. A new model was therefore proposed to predict this behavior by the use of a variable coefficient of diffusion in Fick's diffusion equation. However, simulation work on the mechanical properties after hygrothermal aging was not considered by the author. Pan and Zhong. [2015b] proposed an analytical model to calculate the modulus of hybrid composites with moisture based on the Rule of Hybrid Mixtures. Both natural fibers and polymers absorbed moisture. Consequently, the composites would swell and experience property degradation. An internal variable was introduced to represent the effects of moisture saturation. This internal variable exerted a deterioration effect on the elastic properties, which were expressed as follows:

$$
E_{C}=\left(1-\beta_{1} \cdot \alpha\right)\left(E_{C}^{(1)} \cdot f^{(1]}+E_{C}^{(2)} \cdot f^{(2)}\right)
$$

where $\beta_{1}\left(0 \leq \beta_{1} \leq 1\right)$ is defined as the degradation parameter of fiber/matrix interfacial damage and $\alpha(0 \leq \alpha \leq 1)$ is the internal variable. For both dry and saturated samples, the Rule of Hybrid Mixtures predicted a linear relationship between the modulus and relative fiber content of the hybrid fiber composites. This was verified by test results. The accuracy of this model seemed to be acceptable after comparison with experimental observations.

Regazzi et al. 2016] modeled the moisture diffusion and subsequent swelling and plasticizing in Poly (lactic acid) (PLA) and PLA/flax composites. A numerical model accounting for water diffusion, the resulting swelling and plasticizing of polymers was implemented. For water diffusion, Fick diffusion was considered as the diffusion mode. For the modeling of swelling, local strain was mostly considered to be proportional to local water content. A swelling tensor was defined which mainly involved swelling coefficients and water content. For the modeling of plasticizing, third degree polynomial functions were implemented in the numerical model to provide local moduli depending on the local water content. Both water content and modulus of PLA and flax/PLA composites as functions of immersion time at different aging temperatures were predicted. It is noted that only reversible phenomenon (without polymer relaxation and hydrolysis) was successfully simulated. Simulated data proved to be in perfect accordance with experimental results as long as no irreversible mechanism was occurring. The deviations of the simulated data from experimental results were limited at $35^{\circ} \mathrm{C}$ but significant at $50^{\circ} \mathrm{C}$. 


\section{Conclusions}

Considering the lack of relevant review in the literature focusing on the simulation of the mechanical behavior of natural plant fiber composites, this paper presents and summarizes the latest research work on plant fiber composites that need to be acquainted prior to their mechanical property prediction. The microstructure and mechanical properties of natural plant fiber composites are introduced with emphases placed on their possible influences on subsequent simulation process. The sound and vibration damping properties are introduced to highlight the multifunctional aspects of natural plant fiber composites. Important contributions to analytical and numerical prediction of natural plant fiber composites that were reported in the literature are discussed. It is found that compared to carbon and glass fibers, analytical and numerical work on natural plant fiber composites are rarely reported. The existing technical challenges are particularly identified and presented. These challenges suggest the thrust for future research.

\section{References}

Adekomaya, O., Jamiru, T., Sadiku, R. and Huan, Z. [2016] "A review on the sustainability of natural fiber in matrix reinforcement - A practical perspective," Journal of Reinforced Plastics and Composites 35(1), 3-7.

Ahmad, F., Choi, H. S. and Park, M. K. [2015] "A review: Natural fiber composites selection in view of mechanical, light weight, and economic properties," Macromolecular Materials and Engineering 300(1), 10-24.

Akil, H. M., Omar, M. F., Mazuki, A. A. M., Safiee, S., Ishak, Z. A. M. and Abu Bakar, A. [2011] "Kenaf fiber reinforced composites: A review," Materials $\&$ Design 32(8-9), $4107-4121$.

Al-Oqla, F. M. and Sapuan, S. M. [2014] "Natural fiber reinforced polymer composites in industrial applications: Feasibility of date palm fibers for sustainable automotive industry," Journal of Cleaner Production 66, 347-354.

Andersons, J. and Joffe, R. [2011] "Estimation of the tensile strength of an oriented flax fiber-reinforced polymer composite," Composites Part A: Applied Science and Manufacturing 42(9), 1229-1235.

Andersons, J., Joffe, R., Spãrniņŝ, E. and Weichert, D. [2011] "Modeling the effect of reinforcement discontinuity on the tensile strength of UD flax fiber composites," Journal of Materials Science 46(15), 5104-5110.

Andersons, J., Sparniņš, E., Joffe, R. and Wallström, L. [2005] "Strength distribution of elementary flax fibers," Composites Science and Technology 65(3-4), 693-702.

Andersons, J., Sparniņš, E. and Joffe, R. [2006] "Stiffness and strength of flax fiber/polymer matrix composites," Polymer Composites 27(2), 221-229.

Andersons, J., Porie, E. and Sparniņš, E. [2009] "The effect of mechanical defects on the strength distribution of elementary flax fibres," Composites Science and Technology 69(13), 2152-2157.

Arbelaiz, A., Fernández, B., Cantero, G., Llano-Ponte, R., Valea, A. and Mondragon, I. [2005a] "Mechanical properties of flax fibre/polypropylene composites. Influence of fibre/matrix modification and glass fibre hybridization," Composites Part A: Applied Science and Manufacturing 36(12), 1637-1644. 
Arbelaiz, A., Fernández, B., Ramos, J. A., Retegi, A., Llano-Ponte, R. and Mondragon, I. [2005b] "Mechanical properties of short flax fibre bundle/polypropylene composites: Influence of matrix/fibre modification, fibre content, water uptake and recycling," Composites Science and Technology 65(10), 1582-1592.

Asdrubali, F., Schiavoni, S. and Horoshenkov, K. V. [2012] "A review of sustainable materials for acoustic applications," Building Acoustics 19(4), 283-312.

Ashworth, S., Rongong, J., Wilson, P. and Meredith, J. [2016] "Mechanical and damping properties of resin transfer moulded jute-carbon hybrid composites," Composites Part B: Engineering 105, 60-66.

Astley, O. M. and Donald, A. M. [2003] "The tensile deformation of flax fibers as studied by X-ray scattering," Journal of Materials Science 38(1), 165-171.

Baley, C. [2002] "Analysis of the flax fibers tensile behavior and analysis of the tensile stiffness increase," Composites — Part A: Applied Science and Manufacturing 33(7), 939-948.

Bax, B. and Müssig, J. [2008] "Impact and tensile properties of PLA/Cordenka and PLA/flax composites," Composites Science and Technology 68(7-8), 16011607.

Beakou, A. and Charlet, K. [2013] "Mechanical properties of interfaces within a flax bundlePart II: Numerical analysis," International Journal of Adhesion and Adhesives 43, 54-59.

Beckermann, G. W. and Pickering, K. L. [2009] "Engineering and evaluation of hemp fiber reinforced polypropylene composites: Micro-mechanics and strength prediction modeling," Composites Part A: Applied Science and Manufacturing 40(2), $210-217$.

Belingardi, G., Mehdipour, H., Mangino, E. and Martorana, B. [2016] "Progressive damage analysis of a rate-dependent hybrid composite beam," Composite Structures 154, 433-442.

Berardi, U. and Iannace, G. [2015] "Acoustic characterization of natural fibers for sound absorption applications," Building and Environment 94, 840-852.

Bharath, K. N. and Basavarajappa, S. [2016] "Applications of biocomposite materials based on natural fibers from renewable resources: A review," Science and Engineering of Composite Materials 23(2), 123-133.

Blanchard, J. M. F. A., Sobey, A. J. and Blake, J. I. R. [2016] "Multi-scale investigation into the mechanical behavior of flax in yarn, cloth and laminate form," Composites Part B: Engineering 84, 228-235.

Bos, H. L., Van Den Oever, M. J. A. and Peters, O. C. J. J. [2002] "Tensile and compressive properties of flax fibers for natural fiber reinforced composites," Journal of Materials Science 37(8), 1683-1692.

Cao, S., Wang, X. and Wu, Z. [2011] "Evaluation and prediction of temperature-dependent tensile strength of unidirectional carbon fiber-reinforced polymer composites," Journal of Reinforced Plastics and Composites 30(9), 799-807.

Charlet, K., Baley, C., Morvan, C., Jernot, J. P., Gomina, M. and Bréard, J. [2007] "Characteristics of Hermès flax fibers as a function of their location in the stem and properties of the derived unidirectional composites," Composites Part A: Applied Science and Manufacturing 38(8), 1912-1921.

Charlet, K., Eve, S., Jernot, J. P., Gomina, M. and Breard, J. [2009] "Tensile deformation of a flax fiber," Procedia Engineering 1(1), 233-236.

Charlet, K., Jernot, J.-P., Breard, J. and Gomina, M. [2010b] "Scattering of morphological and mechanical properties of flax fibres," Industrial Crops and Products 32(3), $220-224$. 
Charlet, K., Jernot, J. P., Eve, S., Gomina, M. and Bréard, J. [2010a] "Multi-scale morphological characterization of flax: From the stem to the fibrils," Carbohydrate Polymers $\mathbf{8 2}(1), 54-61$.

Chen, D., Li, J. and Ren, J. [2010] "Study on sound absorption property of ramie fiber reinforced poly (l-lactic acid) composites: Morphology and properties," Composites Part A: Applied Science and Manufacturing 41(8), 1012-1018.

Christian, S. J. and Billington, S. L. [2011] "Mechanical response of PHB- and cellulose acetate natural fiber-reinforced composites for construction applications," Composites Part B: Engineering 42(7), 1920-1928.

Cox, H. L. [1952] "The elasticity and strength of paper and other fibrous materials," British Journal of Applied Physics 3(3), 72-79.

Davies, G. C. and Bruce, D. M. [1998] "Effect of environmental relative humidity and damage on the tensile properties of flax and nettle fibers," Textile Research Journal 68(9), 623-629.

Davoodi, M. M., Sapuan, S. M., Ahmad, D., Aidy, A., Khalina, A. and Jonoobi, M. [2011] "Concept selection of car bumper beam with developed hybrid bio-composite material," Materials and Design 32(10), 4857-4865.

Defoirdt, N., Biswas, S., Vriese, L. D., Tran, L. Q. N., Acker, J. V., Ahsan, Q., Gorbatikh, L., Vuure, A. V. and Verpoest, I. [2010] "Assessment of the tensile properties of coir, bamboo and jute fibre," Composites Part A: Applied Science and Manufacturing 41(5), 588-595.

Delany, M. E. and Bazley, E. N. [1970] "Acoustical properties of fibrous absorbent materials," Applied Acoustics 3(2), 105-116.

Dhakal, H. N., Zhang, Z. Y., Guthrie, R., MacMullen, J. and Bennett, N. [2013] "Development of flax/carbon fibre hybrid composites for enhanced properties," Carbohydrate Polymers 96(1), 1-8.

Dhakal, H. N., Zhang, Z. Y. and Richardson, M. O. W. [2007] "Effect of water absorption on the mechanical properties of hemp fiber reinforced unsaturated polyester composites," Composites Science and Technology 67(7-8), 1674-1683.

Daoud, H., Rebière, J.-L., Makni, A., Taktak, M., Mahi, A. E. and Haddar, M. [2016] "Numerical and experimental characterization of the dynamic properties of flax fiber reinforced composites," International Journal of Applied Mechanics 8(5), 1650068.

Duc, F., Bourban, P. E., Plummer, C. J. G. and Månson, J.-A. E. [2014] "Damping of thermoset and thermoplastic flax fibre composites," Composites Part A: Applied Science and Manufacturing 64, 115-123.

Facca, A. G., Kortschot, M. T. and Yan, N. [2007] "Predicting the tensile strength of natural fiber reinforced thermoplastics," Composites Science and Technology 67(1112), 2454-2466.

Faruk, O., Bledzki, A. K., Fink, H.-P. and Sain, M. [2012] "Biocomposites reinforced with natural fibers: 2000-2010," Progress in Polymer Science 37(11), 1552-1596.

Faruk, O., Bledzki, A. K., Fink, H.-P. and Sain, M. [2014] "Progress report on natural fiber reinforced composites," Macromolecular Materials and Engineering 299(1), 9-26.

Fatima, S. and Mohanty, A. R. [2011] "Acoustical and fire-retardant properties of jute composite materials," Applied Acoustics 72(2-3), 108-114.

Flynn, J., Amiri, A. and Ulven, C. [2016] "Hybridized carbon and flax fiber composites for tailored performance," Materials and Design 102, 21-29.

Fu, S.-Y., Xu, G. and Mai, Y.-W. [2002] "On the elastic modulus of hybrid particle/shortfiber/polymer composites," Composites Part B: Engineering 33(4), 291-299. 
Gao, J., Li, J., Benicewicz, B. C., Zhao, S., Hillborg, H. and Schadler, L. S. [2012] "The mechanical properties of epoxy composites filled with rubbery copolymer grafted $\mathrm{SiO}_{2}, "$ Polymers 4(1), 187-210.

Garai, M. and Pompoli, F. [2005] "A simple empirical model of polyester fibre materials for acoustical applications," Applied Acoustics 66(12), 1383-1398.

Garkhail, S. K., Heijenrath, R. W. H. and Peijs, T. [2000] "Mechanical properties of natural-fibre-mat- reinforced thermoplastics based on flax fibres and polypropylene," Applied Composite Materials 7(5), 351-372.

George, M., Mussone, P. G., Alemaskin, K., Chae, M., Wolodko, J. and Bressler, D. C. [2016] "Enzymatically treated natural fibres as reinforcing agents for biocomposite material: Mechanical, thermal, and moisture absorption characterization," Journal of Materials Science 51(5), 2677-2686.

Gurunathan, T., Mohanty, S. and Nayak, S. K. [2015] "A review of the recent developments in biocomposites based on natural fibers and their application perspectives," Composites Part A: Applied Science and Manufacturing 77, 1-25.

Hajj, N. E., Mboumba-Mamboundou, B., Dheilly, R.-M., Aboura, Z., Benzeggagh, M. and Queneudec, M. [2011] "Development of thermal insulating and sound absorbing agro-sourced materials from auto linked flax-tows," Industrial Crops and Products 34(1), 921-928.

Holbery, J. and Houston, D. [2006] "Natural-fiber-reinforced polymer composites in automotive applications," JOM 58(11), 80-86.

Huda, S., Reddy, N. and Yang, Y. [2012] "Ultra-light-weight composites from bamboo strips and polypropylene web with exceptional flexural properties," Composites Part B: Engineering 43(3), 1658-1664.

Kalia, S., Kaith, B. S. and Kaur, I. [2009] "Pretreatments of natural fibers and their application as reinforcing material in polymer composites-a review," Polymer Engineering and Science 49(7), 1253-1272.

Kalyankar, R. R. and Uddin, N. [2012] "Structural characterization of natural fiber reinforced polymeric (NFRP) laminates for building construction," Journal of Polymers and the Environment 20(1), 224-229.

Karus, M. and Kaup, M. [2002] "Natural fibers in the european automotive industry," Journal of Industrial Hemp 7(1), 119-131.

Kebir, H. and Ayad, R. [2014] "A specific finite element procedure for the analysis of elastic behavior of short fibre reinforced composites. The projected fiber approach," Composite Structures 118, 580-588.

Kellersztein, I. and Dotan, A. [2016] "Chemical surface modification of wheat straw fibers for polypropylene reinforcement," Polymer Composites 37(7), 2133-2141.

Khot, S. N., Lascala, J. J., Can, E., Morye, S. S., Williams, G. I., Palmese, G. R., Kusefoglu, S. H. and Wool, R. P. [2001] "Development and application of triglyceridebased polymers and composites," Journal of Applied Polymer Science 82(3), 703-723.

Kong, C., Lee, H. and Park, H. [2016] "Design and manufacturing of automobile hood using natural composite structure," Composites Part B: Engineering 91, 18-26.

Korjenic, A., Zach, J. and Hroudová, J. [2016] "The use of insulating materials based on natural fibers in combination with plant facades in building constructions," Energy and Buildings 116, 45-58.

Koronis, G., Silva, A. and Fontul, M. [2013] "Green composites: A review of adequate materials for automotive applications," Composites Part B: Engineering 44(1), $120-127$. 
Ku, H., Wang, H., Pattarachaiyakoop, N. and Trada, M. [2011] "A review on the tensile properties of natural fiber reinforced polymer composites," Composites Part B: Engineering 42(4), 856-873.

Lamon, J., R'Mili, M. and Reveron, H. [2016] "Investigation of statistical distributions of fracture strengths for flax fibre using the tow-based approach," Journal of Materials Science 51(18), 8687-8698.

Lampeas, G. and Fotopoulos, K. [2015] "Interlaminar stresses calculation using a stackedshell finite element modeling approach," International Journal of Applied Mechanics $7(5), 1550067$.

Le Duigou, A. and Baley, C. [2014] "Coupled micromechanical analysis and life cycle assessment as an integrated tool for natural fibre composites development," Journal of Cleaner Production 83, 61-69.

Lefeuvre, A., Bourmaud, A., Morvan, C. and Baley, C. [2014] "Tensile properties of elementary fibres of flax and glass: Analysis of reproducibility and scattering," Materials Letters 130, 289-291.

Li, W., Cai, H., Li, C., Wang, K. and Fang, L. [2015] "Micro-mechanics of failure for fatigue strength prediction of bolted joint structures of carbon fiber reinforced polymer composite," Composite Structures 124, 345-356.

Liu, P. F., Gu, Z. P., Yang, Y. H. and Peng, X. Q. [2016] "A nonlocal finite element model for progressive failure analysis of composite laminates," Composites Part B: Engineering 86, 178-196.

Maity, S., Gon, D. P. and Paul, P. [2014] "A review of flax nonwovens: Manufacturing, properties, and applications," Journal of Natural Fibers 11(4), 365-390.

Marsh, G. [2003] "Next step for automotive materials," Materials Today 6(4), 36-43.

Meredith, J., Ebsworth, R., Coles, S. R., Wood, B. M. and Kirwan, K. [2012] "Natural fiber composite energy absorption structures," Composites Science and Technology 72(2), 211-217.

Mirbagheri, J., Tajvidi, M., Hermanson, J. C. and Ghasemi, I. [2007] "Tensile properties of wood flour/kenaf fiber polypropylene hybrid composites," Journal of Applied Polymer Science 105(5), 3054-3059.

Misri, S., Sapuan, S. M., Leman, Z. and Ishak, M. R. [2015] "Torsional behavior of filament wound kenaf yarn fibre reinforced unsaturated polyester composite hollow shafts," Materials and Design 65, 953-960.

Modniks, J., Porie, E., Andersons, J. and Joffe, R. [2012] "Evaluation of the apparent interfacial shear strength in short-flax-fiber/PP composites," Mechanics of Composite Materials 48(5), 571-578.

Mohammed, L., Ansari, M. N. M., Pua, G., Jawaid, M. and Islam, M. S. [2015] "A review on natural fiber reinforced polymer composite and its applications," International Journal of Polymer Science, doi:10.1155/2015/243947.

Mohanty, A. K., Misra, M. and Drzal, L. T. [2002] "Sustainable bio-composites from renewable resources: Opportunities and challenges in the green materials world," Journal of Polymers and the Environment 10(1-2), 19-26.

Mueller, D. H. and Krobjilowski, A. [2003] "New discovery in the properties of composites reinforced with natural fibers," Journal of Industrial Textiles 33(2), 111-129.

Müssig, J., Herrmann, A. S. and Rau, S. [2006] "Influence of fineness, stiffness and loaddisplacement characteristics of natural fibers on the properties of natural fiberreinforced polymers," Journal of Natural Fibers 3(1), 59-80.

Nadlene, R., Sapuan, S. M., Jawaid, M., Ishak, M. R. and Yusriah, L. [2016] "A review on roselle fiber and its composites," Journal of Natural Fibers 13(1), 10-41.

Natural fibers. http://www.naturalfibres2009.org/en/fibres/flax.html. 
Neagu, R. C., Gamstedt, E. K. and Berthold, F. [2006] "Stiffness contribution of various wood fibers to composite materials," Journal of Composite Materials 40(8), 663-699.

$\mathrm{Ni}, \mathrm{C}$. and Wei, G. [2016] "Geometric model and elastic constant prediction of 3d fourstep braided composites based on the cubic spline curve," International Journal of Applied Mechanics 8(2), 1650019.

Nirbhay, M., Misra, R. K. and Dixit, A. [2015] "Finite-element analysis of jute - and coir-fiber-reinforced hybrid composite multipanel plates," Mechanics of Composite Materials 51(4), 505-520.

Nobeen, N. S., Zhong, Y., Francis, B. A. P., Ji, X., Chia, E. S. M., Joshi, S. C. and Chen, Z. [2016] "Constituent materials micro-damage modeling in predicting progressive failure of braided fiber composites," Composite Structures 145, 194-202.

Nor, M. J. M., Ayub, M., Zulkifli, R., Amin, N. and Fouladi, M. H. [2010] "Effect of different factors on the acoustic absorption of coir fiber," Journal of Applied Sciences 10(22), $2887-2892$.

Oksman, K., Skrifvars, M. and Selin, J.-F. [2003] "Natural fibers as reinforcement in polylactic acid (PLA) composites," Composites Science and Technology 63(9), 13171324.

Olmedo, Á. and Santiuste, C. [2012] "On the prediction of bolted single-lap composite joints," Composite Structures 94(6), 2110-2117.

Pan, Y. and Zhong, Z. [2015a] "A micromechanical model for the mechanical degradation of natural fiber reinforced composites induced by moisture absorption," Mechanics of Materials 85, 7-15.

Pan, Y. and Zhong, Z. [2015b] "The effect of hybridization on moisture absorption and mechanical degradation of natural fiber composites: An analytical approach," Composites Science and Technology 110, 132-137.

Panamoottil, S. M., Das, R. and Jayaraman, K. [2016] "Anisotropic continuum damage model for prediction of failure in flax/polypropylene fabric composites," Polymer Composites 37(8), 2588-2597.

Parikh, D. V., Chen, Y. and Sun, L. [2006] "Reducing automotive interior noise with natural fiber nonwoven floor covering systems," Textile Research Journal 76 (11), $813-820$.

Park, H. [2016] "A study on structural design and analysis of small wind turbine blade with natural fiber (flax) composite," Advanced Composite Materials 25(2), 125-142.

Phillips, S. and Lessard, L. [2012] "Application of natural fiber composites to musical instrument top plates," Journal of Composite Materials 46(2), 145-154.

Pickering, K. L., Efendy, M. G. A. and Le, T. M. [2016] "A review of recent developments in natural fiber composites and their mechanical performance," Composites Part A: Applied Science and Manufacturing 83, 98-112.

Pil, L., Bensadoun, F., Pariset, J. and Verpoest, I. [2016] "Why are designers fascinated by flax and hemp fibre composites?" Composites Part A: Applied Science and Manufacturing 83, 193-205.

Pupure, L., Varna, J. and Joffe, R. [2016] "Natural fiber composite: Challenges simulating inelastic response in strain-controlled tensile tests," Journal of Composite Materials $\mathbf{5 0}(5), 575-587$.

Rasmussen, K. J. R. [2003] "Full-range stress-strain curves for stainless steel alloys," Journal of Constructional Steel Research 59(1), 47-61.

Regazzi, A., Léger, R., Corn, S. and Ienny, P. [2016] "Modeling of hydrothermal aging of short flax fiber reinforced composites," Composites Part A: Applied Science and Manufacturing 90, 559-566. 
Rubio-López, A., Hoang, T. and Santiuste, C. [2016] "Constitutive model to predict the viscoplastic behavior of natural fibres based composites," Composite Structures $\mathbf{1 5 5}$, $8-18$.

Rwawiire, S., Tomkova, B., Militky, J., Hes, L. and Kale, B. M. [2017] "Acoustic and thermal properties of a cellulose nonwoven natural fabric (barkcloth)," Applied Acoustics 116, $177-183$.

Saba, N., Jawaid, M., Alothman, O. Y. and Paridah, M. T. [2016] "A review on dynamic mechanical properties of natural fiber reinforced polymer composites," Construction and Building Materials 106, 149-159.

Saidane, E. H., Scida, D., Assarar, M., Sabhi, H. and Ayad, R. [2016] "Hybridisation effect on diffusion kinetic and tensile mechanical behavior of epoxy based flax-glass composites," Composites Part A: Applied Science and Manufacturing 87, 153-160.

Sanyang, M. L., Sapuan, S. M., Jawaid, M., Ishak, M. R. and Sahari, J. [2016] "Recent developments in sugar palm (Arenga pinnata) based biocomposites and their potential industrial applications: A review," Renewable and Sustainable Energy Reviews $\mathbf{5 4}, 533-549$.

Sargianis, J. J., Kim, H.-I., Andres, E. and Suhr, J. [2013] "Sound and vibration damping characteristics in natural material based sandwich composites," Composite Structures 96, 538-544.

Scarponi, C. and Messano, M. [2015] "Comparative evaluation between E-Glass and hemp fiber composites application in rotorcraft interiors," Composites Part B: Engineering 69, 542-549.

Shah, D. U. [2016] "Damage in biocomposites: Stiffness evolution of aligned plant fibre composites during monotonic and cyclic fatigue loading," Composites Part A: Applied Science and Manufacturing 83, 160-168.

Shahzad, A. [2012] "Hemp fiber and its composites - A review," Journal of Composite Materials 46(8), 973-986.

Sliseris, J., Yan, L. and Kasal, B. [2016] "Numerical modeling of flax short fiber reinforced and flax fiber fabric reinforced polymer composites," Composites Part B: Engineering 89, 143-154.

Summerscales, J., Dissanayake, N. P. J., Virk, A. S. and Hall, W. [2010] "A review of bast fibres and their composites. Part 1 - Fibres as reinforcements," Composites Part A: Applied Science and Manufacturing 41(10), 1329-1335.

Summerscales, J., Virk, A. and Hall, W. [2013] "A review of bast fibers and their composites: Part 3-modeling," Composites Part A: Applied Science and Manufacturing 44(1), 132-139.

Tay, T. E., Liu, G., Tan, V. B. C., Sun, X. S. and Pham, D. C. [2008] "Progressive failure analysis of composites," Journal of Composite Materials 42(18), 1921-1966.

Tayfun, U., Dogan, M. and Bayramli, E. [2016] "Influence of surface modifications of flax fiber on mechanical and flow properties of thermoplastic polyurethane based ecocomposites," Journal of Natural Fibers 13(3), 309-320.

Thilagavathi, G., Pradeep, E., Kannaian, T. and Sasikala, L. [2010] "Development of natural fiber nonwovens for application as car interiors for noise control," Journal of Industrial Textiles 39(3), 267-278.

Thomason, J. L. and Vlug, M. A. [1996] "Influence of fibre length and concentration on the properties of glass fibre-reinforced polypropylene: 1. Tensile and flexural modulus," Composites Part A: Applied Science and Manufacturing 27(6), 477-484.

Thwe, M. M. and Liao, K. [2002] "Effects of environmental aging on the mechanical properties of bamboo-glass fiber reinforced polymer matrix hybrid composites," Composites - Part A: Applied Science and Manufacturing 33(1), 43-52. 
Toubal, L., Cuillière, J.-C., Bensalem, K., Francois, V. and Gning, P.-B. [2016] "Hygrothermal effect on moisture kinetics and mechanical properties of hemp/polypropylene composite: Experimental and numerical studies," Polymer Composites 37(8), 23422352 .

Turan, K. and Pekbey, Y. [2014] "Progressive failure analysis of reinforced-adhesively single-lap joint," Journal of Adhesion 91(12), 962-977.

Väisänen, T., Haapala, A., Lappalainen, R. and Tomppo, L. [2016] "Utilization of agricultural and forest industry waste and residues in natural fiber-polymer composites: A review," Waste Management 54, 62-73.

Van de Weyenberg, I., Ivens, J., De Coster, A., Kino, B., Baetens, E. and Verpoest, I. [2003] "Influence of processing and chemical treatment of flax fibres on their composites," Composites Science and Technology 63(9), 1241-1246.

Venkateshwaran, N., Elayaperumal, A. and Sathiya, G. K. [2012] "Prediction of tensile properties of hybrid-natural fiber composites," Composites Part B: Engineering 43(2), 793-796.

Virk, A. S., Hall, W. and Summerscales, J. [2010] "Failure strain as the key design criterion for fracture of natural fiber composites," Composites Science and Technology 70(6), 995-999.

Virk, A. S., Hall, W. and Summerscales, J. [2011] "modeling tensile properties of jute fibers," Materials Science and Technology 27(1), 458-460.

Wambua, P., Ivens, J. and Verpoest, I. [2003] "Natural fibres: Can they replace glass in fibre reinforced plastics?" Composites Science and Technology 63(9), 1259-1264.

Wang, F., Li, X., Zhang, J., Li, L. and Keer, L. M. [2016b] "Micromechanical modeling of the progressive failure in unidirectional composites reinforced with bamboo fibres," Mechanics of Materials 94, 180-192.

Wang, C., Zhong, Y., Bernad Adaikalaraj, P. F., Ji, X., Roy, A., Silberschmidt, V. V. and Chen, Z. [2016a] "Strength prediction for bi-axial braided composites by a multi-scale modeling approach," Journal of Materials Science 51(12), 6002-6018.

Yan, L. B., Chouw, N. and Jayaraman, K. [2014] "Flax fiber and its composites - A review," Composites Part B: Engineering 56, 296-317.

Yang, W. D. and Li, Y. [2012] "Sound absorption performance of natural fibers and their composites," Science China Technological Sciences 55(8), 2278-2283.

Yim, S. O., Lee, W. J., Cho, D. H. and Park, I. M. [2015] "Finite element analysis of compressive behavior of hybrid short fiber/particle/Mg metal matrix composites using RVE model," Metals and Materials International 21(2), 408-414.

Young, B. [2008] "Experimental and numerical investigation of high strength stainless steel structures," Journal of Constructional Steel Research 64(11), 1225-1230.

Zafeiropoulos, N. E., Williams, D. R., Baillie, C. A. and Matthews, F. L. [2002a] "Engineering and characterisation of the interface in flax fibre/polypropylene composite materials. Part I. Development and investigation of surface treatments," Composites Part A: Applied Science and Manufacturing 33(8), 1083-1093.

Zafeiropoulos, N. E., Baillie, C. A. and Hodgkinson, J. M. [2002b] "Engineering and characterisation of the interface in flax fibre/polypropylene composite materials. Part II. The effect of surface treatments on the interface," Composites Part A: Applied Science and Manufacturing 33(9), 1185-1190.

Zeng, X., Mooney, S. J. and Sturrock, C. J. [2015] "Assessing the effect of fibre extraction processes on the strength of flax fibre reinforcement," Composites Part A: Applied Science and Manufacturing 70, 1-7. 
Zhang, B. M. and Zhao, L. [2011] "Progressive damage and failure modeling in fiberreinforced laminated composites containing a hole," International Journal of Damage Mechanics 21(6), 893-911.

Zhong, Y. and Joshi, S. C. [2015] "Response of hygrothermally aged GLARE 4A laminates under static and cyclic loadings," Materials and Design 87, 138-148.

Zhong, Y. and Joshi, S. C. [2016] "Environmental durability of glass fiber epoxy composites filled with core-shell polymer particles," Materials and Design 92, 866-879. 